\title{
Characterization of nickel-doped biphasic calcium phosphate/graphene nanoplatelet composites for biomedical application
}

\author{
S. Baradaran a,*, E. Moghaddam ' ${ }^{\text {, Bahman Nasiri-Tabrizi c,*, W.J. Basirun d,e, M. Mehrali a,f , M. Sookhakiann }}{ }^{\text {, }}$, \\ M. Hamdi ${ }^{\text {h }}$, Y. Alias ${ }^{\mathrm{d}}$ \\ ${ }^{a}$ Department of Mechanical Engineering Faculty of Engineering University of Malaya, 50603 Kuala Lumpur, Malaysia \\ b Tropical Infectious Diseases Research and Education Centre, Department of Medical Microbiology, Faculty of Medicine, University of Malaya, 50603 Kuala Lumpur, Malaysia \\ c Advanced Materials Research Center, Materials Engineering Department, Najafabad Branch, Islamic Azad University, Ifahan, Iran \\ ${ }^{d}$ Department of Chemistry, Faculty of Science, University of Malaya, Kuala Lumpur 50603, Malaysia \\ e Institute of Nanotechnology\& Catalysis Research (NanoCat), University Malaya, 50603 Kuala Lumpur, Malaysia \\ ${ }^{\mathrm{f}}$ Department of Biomedical Engineering, Faculty of Engineering University of Malaya, Kuala Lumpur 50603, Malaysia \\ ${ }^{\mathrm{g}}$ Department of Physics, Faculty of Science, University of Malaya, Kuala Lumpur 50603, Malaysia \\ h Center of Advanced Manufacturing and Material Processing, University of Malaya, 50603 Kuala Lumpur, Malaysi
}

A R T I C L E I N F O

\section{Article history:}

Received 24 October 2014

Received in revised form 30 December 2014

Accepted 10 January 2015

Available online 15 January 2015

\section{Keywords:}

Biomaterials

Sintering

Electron microscopy

Fracture and toughness

Graphene nanoplatele

Biological properties
A B S T R A C T

The effect of the addition of an ionic dopant to calcium phosphates for biomedical applications requires specific research due to the essential roles played in such processes. In the present study, the mechanical and biological properties of Ni-doped hydroxyapatite (HA) and Ni-doped HA mixed with graphene nanoplatelets (GNPs) were evaluated. $\mathrm{Ni}$ ( $3 \mathrm{wt} . \%$ and $6 \mathrm{wt} . \%$ )-doped $\mathrm{HA}$ was synthesized using a continuous precipitation method and calcined at $900{ }^{\circ} \mathrm{C}$ for $1 \mathrm{~h}$. The GNP $(0.5-2$ wt.\%)-reinforced $6 \%$ Ni-doped HA (Ni6) composite was prepared using rotary ball milling for $15 \mathrm{~h}$. The sintering process was performed using hot isostatic pressing at processing conditions of $1150^{\circ} \mathrm{C}$ and $160 \mathrm{MPa}$ with a 1-h holding time. The results indicated that the phase compositions and structural features of the products were noticeably affected by the Ni and GNPs. The mechanical properties of Ni6 and $1.5 \mathrm{Ni} 6$ were increased by $55 \%$ and $75 \%$ in hardness, $59 \%$ and $163 \%$ in fracture toughness and $120 \%$ and $85 \%$ in elastic modulus compared with monolithic HA, respectively. The in-vitro biological behavior was investigated using h-FOB osteoblast cells in 1, 3 and 5 days of culture. Based on the osteoblast results, the cytotoxicity of the products was indeed affected by the Ni doping. In addition, the effect of GNPs on the growth and proliferation of osteoblast cells was investigated in Ni6 composites containing different ratios of GNPs, where $1.5 \mathrm{wt}$ \% was the optimum value.

(C) 2015 Elsevier B.V. All rights reserved.

\section{Introduction}

One of the most exciting areas in engineering disciplines involves the development of various devices for health care. Calcium phosphate (CP)-based biomaterials have attracted great attention as bone replacements due to their similarity in composition and crystal structure to bone minerals, excellent biocompatibility, bioactivity and biodegradability. However, it is imperative to understand the mechanical responses of artificially grown calcium phosphate ceramics [1]. Some of the CPs are implantable in applications such as fracture fixation plates, nails and screws in orthopedics, orthodontic wires, total joint replacement prostheses, etc. [2,3]. Among these bioceramics, the most wellknown and extensively used compounds are hydroxyapatite (HA) and tricalcium phosphate (TCP) for medical implants, bone defect fillers

\footnotetext{
* Corresponding authors.

E-mail addresses: saeid_baradaran@yahoo.com (S. Baradaran), bahman_nasiri@hotmail.com (B. Nasiri-Tabrizi).
}

and bone tissue engineering $[4,5]$. However, many reports have mentioned the limitation of using HA and TCP due to the resulting high insolubility and poor mechanical properties, such as low ductility and brittleness, which in turn cause implant loosening and subsequent implant failure [6]. Therefore, biomaterial engineers have focused on improving the composite properties using different types of materials and synthetic techniques. Crystal structure modification of HA via ionic substitution to enhance the solubility and biological properties has attracted considerable attention. In the past two decades, there have been several studies on the substitution of calcium in apatite compounds with various metal ions such as monovalent $\left(\mathrm{Ag}^{+}\right.$and $\left.\mathrm{Na}^{+}\right)$[7,8], divalent $\left(\mathrm{Mg}^{2+}, \mathrm{Mn}^{2+}, \mathrm{Sr}^{2+}, \mathrm{Cd}^{2+}\right.$ and $\left.\mathrm{Pb}^{2+}\right)[9-13]$ and trivalent $\left(\mathrm{La}^{3+}, \mathrm{Y}^{3+}, \mathrm{In}^{3+}, \mathrm{Ga}^{3+}\right.$ and $\left.\mathrm{Eu}^{3+}\right)$ ions [14-18]. The focus of the research objectives is the improvement of the bioactivity and osteoinductivity compared with pure HA; however, only a few studies have investigated the effect of such substitution on the mechanical properties of HA $[19,20]$. Nickel, a first-row transition element, is rarely investigated as a dopant in HA. Nickel possess good mechanical and 
anti-corrosion properties and has attracted much attention as a biomaterial for medical applications [21,22]. However, previous results concerning Ni-doped apatite structures have been rather inconsistent, as outlined below.

Lopez et al. [23] studied HA synthesized in the presence of $\mathrm{Ni}$ and its effect on calcium phosphate formation from aqueous solution. Their results indicated that the presence of $\mathrm{Ni}$ in the solution inhibits calcium hydroxyapatite and octacalcium phosphate formation and may modify the precipitation of octacalcium phosphate. Lopez et al. [24] also investigated the effect of $\mathrm{Ni}$ on the crystallinity and thermal stability of $\mathrm{Ni}$ doped HA solid solutions. The results indicated that Ni decreases the degree of crystallinity and thermal stability of the synthesized materials. In addition, the results indicated that the effect of Ni on HA crystallization is similar to that of $\mathrm{Mg}$ and $\mathrm{Zn}$. Mabilleau et al. [25] investigated the effects of $\mathrm{Ni}^{2+}$ on the HA growth in vitro. These researchers demonstrated that $\mathrm{Ni}^{2+}$ affected the $\mathrm{Ca} / \mathrm{P}$ ratio, crystal size and crystal lattice of $\mathrm{HA}$. Although $\mathrm{Ni}^{2+}$ is a cytotoxic and carcinogenic ion, many medical applications still use Ni-based alloys, such as Ti-Ni super-elastic alloy and $\mathrm{Ni}$-Cr-based alloys, for various applications such as orthodontic wires, orthopedic implants for osteosynthesis, stents for various applications, and bone substitution materials. It should be noted that a high Ni content (approximately 50\%) is of great health concern and is associated with $\mathrm{Ni}^{2+}$ in vitro and in vivo biocompatibility studies. Taira et al. [21] investigated the cytotoxicity of $\mathrm{Ni}^{2+}$ on three fibroblasts, L929, Balb/3T3clone A31 and MC3T3-E1. The results indicated that $\mathrm{Ni}^{2+}$ exhibits dose-dependent cytotoxicity.

In the past two decades, nanotechnology has played a significant role in the advancement of medicine and material science. For instance, carbon-based nanomaterials, especially GNPs, have generated significant interest in the scientific community due to their excellent mechanical and biological properties [26-30]. Recently, several studies on GNPs/HA composites with enhanced mechanical and biological properties due to the presence of GNPs have been reported [6,31-41]. To the best of our knowledge, the effect of graphene on the cellular toxicity and physiochemical properties of metallic ion (especially $\mathrm{Ni}^{2+}$ )-doped $\mathrm{HA}$ is largely unexplored. Thus, the present work assumes significance not only for understanding the biological properties of Ni-doped HA and GNPs composites but also for providing insight into the development of $\mathrm{HA} / \beta$-TCP biphasic (BCP) composites with enhanced mechanical properties. Several experimental techniques, including physical, mechanical and biological testing, were employed to investigate the effect of GNP addition on Ni-doped BCP synthesis. Advances in the general understanding of the phenomena that occur when Ni and GNPs are added to $\mathrm{HA}$ are described.

\section{Materials and methods}

\subsection{Materials}

Calcium nitrate tetrahydrate $\mathrm{Ca}\left(\mathrm{NO}_{3}\right) \cdot 4 \mathrm{H}_{2} \mathrm{O}$, monobasic ammonium dihydrogen-phosphate $\left(\mathrm{NH}_{4}\right) \mathrm{H}_{2} \mathrm{PO}_{4}$, nickel (II) nitrate hexahydrate $\mathrm{Ni}\left(\mathrm{NO}_{3}\right)_{2} \cdot 6 \mathrm{H}_{2} \mathrm{O}$ and ammonium hydroxide solution $\left(\mathrm{NH}_{4} \mathrm{OH}\right)$ were purchased from Sigma Aldrich. Cetyl trimethyl ammonium bromide (CTAB) was selected as the dispersion media. Graphene nanoplatelets (GNPs) were obtained from XG Sciences, Lansing, MI, USA. All the chemicals were of analytical grade and used without further purification.

\subsection{Powders and composite bulk preparation}

Ni-doped HA ( 3 and $6 \mathrm{wt} \%$ ) was synthesized at room temperature using the continuous precipitation method. The desired amounts of $\mathrm{Ca}\left(\mathrm{NO}_{3}\right) \cdot 4 \mathrm{H}_{2} \mathrm{O}$ and $\mathrm{Ni}\left(\mathrm{NO}_{3}\right)_{2} \cdot 6 \mathrm{H}_{2} \mathrm{O}$ were mixed to produce the nitrate solution. This step was followed by the drop-wise addition of $\left(\mathrm{NH}_{4}\right)$ $\mathrm{H}_{2} \mathrm{PO}_{4}$ solution to the nitrate solution under vigorous magnetic stirring. The $\mathrm{pH}$ of the solutions was adjusted with the addition of $\mathrm{NH}_{4} \mathrm{OH}$ to 10 and 11 for $\left(\mathrm{NH}_{4}\right) \mathrm{H}_{2} \mathrm{PO}_{4}$ and nitrate solution, respectively. The suspension was allowed to settle for $24 \mathrm{~h}$ to remove the supernatant. The precipitate was filtered and washed six times with doubly deionized water (DDI). The obtained powder was dried at $100{ }^{\circ} \mathrm{C}$ for $24 \mathrm{~h}$ and calcined at $900{ }^{\circ} \mathrm{C}$ for $1 \mathrm{~h}$. Finally, the powder was ball-milled at $300 \mathrm{rpm}$ in a planetary ball mill (PM 100, Retsch, UK) for $2 \mathrm{~h}$ to produce the fine powder. The respective compounds were labeled $\mathrm{HA}, \mathrm{Ni3}$ and Ni6.

The appropriate quantities of Ni6 powders and GNPs were separately dispersed in DDI with 1 wt.\% CTAB and 1-h sonication. To fabricate the composites, dispersions of GNPs and powders with concentrations of 0.5 wt. $\%, 1$ wt.\%, 1.5 wt.\% and 2 wt.\% GNPs were prepared by sonication for $1 \mathrm{~h}$ followed by planetary ball milling with a zirconia ball and a rotational speed of $400 \mathrm{rpm}$ for $15 \mathrm{~h}$ to obtain a good degree of mixing. The milled slurry mixture was dried in an oven at $90^{\circ} \mathrm{C}$ for $24 \mathrm{~h}$. The dried powders were then pressed at $250 \mathrm{MPa}$ using an uniaxial press to form discs ( $5 \mathrm{~mm}$ in diameter $\times 2 \mathrm{~mm}$ in height) and sintered at $1150{ }^{\circ} \mathrm{C}$ with a 1 -h holding time by hot isostatic pressing (HIP) in a high purity argon gas atmosphere at $160 \mathrm{MPa}$. The heating and cooling rates did not exceed $5{ }^{\circ} \mathrm{C} \mathrm{min}^{-1}$.

\subsection{Sample characterization}

\subsubsection{Physical and chemical characterization}

The relative density for each composition was measured using Archimedean's method using $3.16 \mathrm{~g} \mathrm{~cm}^{-3}, 3.07 \mathrm{~g} \mathrm{~cm}^{-3}$ and $2.2 \mathrm{~g} \mathrm{~cm}^{-3}$ for HA, $\beta$-TCP and GNPs, respectively. The composites were molded with epoxy and polished in a single direction with 600 , 1200 and 2000 grit SiC paper. The final polishing was performed with 9,3 , and $0.5 \mu \mathrm{m}$ polishing compounds to obtain a consistent surface roughness for all of the samples. The surface morphologies of the disc compacts were characterized using field-emission scanning electron microscopy (FESEM, FEI Quanta 200 F). Energy dispersive X-ray spectroscopy (EDS) with an EDS system attached to the FESEM instrument was used to investigate the elemental composition of the samples. Fourier-transform infrared spectroscopy (FTIR) was performed using a Perkin Elmer System series 2000 spectrophotometer (USA) with a frequency range of $400-4000 \mathrm{~cm}^{-1}$. An X-ray diffractometer (PANalytical Empyrean) with $C u K \alpha(\lambda=1.54178 \AA$ ) radiation was used for the phase analysis of the samples. Raman spectroscopy (Renishaw inVia Raman Microscope) was performed to characterize the GNP samples using 514-nm laser excitation, 0.8-mW laser power and 20-um spot sizes.

\subsubsection{Characterization of mechanical properties}

Micro-indentation investigations of the hardness and fracture toughness were performed using a Vickers hardness tester. The elastic modulus measurements from the nanoindentation test were used to measure the fracture toughness. The fracture toughness values were based on three samples with five indents per sample. The indentation fracture toughness was calculated using the Antis equation.

\subsubsection{Mineralization in simulated body fluid (SBF)}

The bioactivity of the sintered samples (with a thickness of $3 \mathrm{~mm}$ and a diameter of $5 \mathrm{~mm}$ ) was evaluated by examining the formation of bone-like apatite on the samples in simulated body fluid (SBF) solution. The sintered samples ( $\mathrm{HA}, \mathrm{Ni} 6$ and $1.5 \mathrm{Ni6}$ ) were soaked in SBF with $\mathrm{pH}(7.4)$ and ion concentrations $\left(\mathrm{Na}^{+} 142.0, \mathrm{~K}^{+} 5.0, \mathrm{Mg}^{2+} 1.5\right.$, $\left.\mathrm{Ca}^{2+} 2.5, \mathrm{Cl}^{-} 147.8, \mathrm{HCO}_{3}^{-} 4.2, \mathrm{HPO}^{2-}{ }_{4} 1.0, \mathrm{SO}^{2-}{ }_{4} 0.5 \mathrm{mM}\right)$ nearly identical to those in human blood plasma [42]. As brief, the SBF was prepared by dissolving reagent-grade mixtures of $\mathrm{CaCl}_{2}, \mathrm{~K}_{2} \mathrm{HPO}_{4} .3 \mathrm{H}_{2} \mathrm{O}, \mathrm{KCl}$, $\mathrm{NaCl}, \mathrm{MgCl}_{2} \cdot \mathrm{H}_{2} \mathrm{O}, \mathrm{NaHCO}_{3}$ and $\mathrm{Na}_{2} \mathrm{SO}_{4}$ in distilled water and buffering at pH 7.4 with tris(hydroxymethyl)aminomethane and hydrochloric acid $(\mathrm{HCl})$. The as sintered samples were soaked in SBF at $37{ }^{\circ} \mathrm{C}$ in a humidified atmosphere containing 5\% CO2 for 7 days at a surface-area-to volume ratio of $0.1 \mathrm{~cm}^{2} / \mathrm{mL}$. The SBF solution was renewed once in 2 days. After 7 days, they were removed from SBF, gently rinsed with 
distilled water, and dried in vacuum at $80^{\circ} \mathrm{C}$. Changes in the surface morphologies of samples after soaking in the SBF were characterized by FESEM equipped with EDX.

\subsubsection{In vitro bone cell-material interactions}

The in vitro cytotoxicity behavior and biocompatibility of the doped, undoped HA and composite samples were evaluated after 1 3 , and 5 days of incubation using human osteoblast cell lines (hFOB 1.19 SV40 transfected osteoblast) that were provided by the American Type Culture Collection (ATCC, Rockville, MD). The cells used were derived from an immortalized osteoblastic cell line, established from DME/F12 solution (Hyclone, Utah, USA) supplemented with a $10 \%$ human fetal bovine serum (Gibco, NY, USA) $100 \mathrm{U} \mathrm{mL}^{-1}$ penicillin and $100 \mathrm{\mu g} \mathrm{mL}^{-1}$ streptomycin in $5 \% \mathrm{CO}_{2}$ and $95 \%$ air atmosphere at $37{ }^{\circ} \mathrm{C}$ in an incubator. All the samples were sterilized by autoclaving at $121^{\circ} \mathrm{C}$ and $15 \mathrm{~atm}$ for $15 \mathrm{~min}$ befor the cell culture experiment. The cells were then seeded onto sample and placed into the wells of a 24 -well plate. The initial cell density was $1 \times 10^{4}$ cells $\mathrm{mL}^{-1}$.

\subsubsection{Cell proliferation using MTT assay}

The methyl thiazole tetrasodium (MTT) assay (Sigma, St. Louis, MO, USA) was performed for 1, 3 and 5 days of incubation to determine the hFOB cell proliferation. Triplicate samples per group were evaluated, and three data points were measured from each sample. An MTT solution of $5 \mathrm{mg} \mathrm{mL}^{-1}$ was prepared by dissolving MTT in PBS and was filter-sterilized using a filter paper with a $0.2-\mu \mathrm{m}$ pore size and stored at $4{ }^{\circ} \mathrm{C}$. Then, $20 \mu \mathrm{l}$ of the MTT solution was added to each sample in the 24-well plates. The cells were then incubated for $4 \mathrm{~h}$ at $37^{\circ} \mathrm{C}$ in humid atmosphere with a $\mathrm{CO}_{2}$ concentration of $5 \%$. After $4 \mathrm{~h}$ of incubation, $100 \mu$ of solubilization/stopping solution was added to each well. Blank and control groups were established to calibrate the cellular survival rate. Only the culture media were added in the blank group. whereas cells and culture media without samples were added in the control group. The optical density (OD) was measured using a 96-wel plate reader (TECAN, Mannendorf, Switzerland) and read by a plate reader at $570 \mathrm{~nm}$. Triplicate samples were used in all the experiment to ensure reproducibility. The data from the MTT assay are presented as means or plotted as \pm SD. Statistical analysis was performed on the MTT assay results using one-way analysis of variance (ANOVA) and a Tukey-Kramer post hoc test using SPSS 19.0; a p-value less than 0.05 was considered significant.

\subsubsection{Cell morphology}

The cell morphology was assessed using FESEM observation afte 1,3 and 5 days of incubation. Cultured samples for SEM observation were rinsed with $0.1 \mathrm{M}$ phosphate-buffered saline (PBS) and fixed with $4 \%$ glutaraldehyde for $2 \mathrm{~h}$ at room temperature. The drying procedure was as follows: the fixed samples were dehydrated in an ethanol series $40 \%, 50 \%, 60 \%, 70 \%, 80 \%, 90 \%$ and $100 \%$ three times followed by the addition of $0.5 \mathrm{~mL}$ of hexamethyldisilane (HMDS to each well to maintain the original morphology of the cell. The dried samples were then platinum coated and examined under a FESEM.

\subsubsection{Confocal laser scanning microscopy}

The samples were washed with $1 \times$ PBS before staining with $100 \mu \mathrm{g} / \mathrm{mL}$ acridine orange (Sigma Aldrich) for $5 \mathrm{~min}$ at room temperature. Excess stain was removed by washing twice with $1 \times$ PBS for $10 \mathrm{~min}$. The stained cells were then analyzed using confocal microscopy (Leica TCS-SP5 II, Leica Microsystem and Mannheim, Germany), and the images were processed with Leica LAS AF software.

\section{Results and discussion}

\subsection{Physical and chemical properties}

\subsubsection{XRD and EDS analysis}

Fig. $1 \mathrm{a}$ and $\mathrm{b}$ presents the XRD profiles of the samples with different degrees of Ni substitution before and after calcination at $900{ }^{\circ} \mathrm{C}$ for $1 \mathrm{~h}$. From Fig. 1a, some distinct features can be recognized upon increasing the $\mathrm{Ni}$ content from 0 to $6 \%$. First, the intensity of the HA characteristic peaks decreased significantly. This behavior is believed to be caused by the amorphization of the product. Second, peak broadening increases with the increase of $\mathrm{Ni}$ substitution because of the structural evolution (crystallite refinement and lattice strain increase). This result indicates that the synthesized powders are nanocrystalline in nature. As observed in Fig. 1b, high-crystalline Ni-doped-HA nanopowders were formed, and no phase transformation or decomposition occurred after the calcination at $900^{\circ} \mathrm{C}$ for $1 \mathrm{~h}$. It is apparent that the characteristic peaks of the calcined samples were more intense than those of the as-prepared powders. This finding suggests that the fraction of the crystalline phase increased after the thermal treatment. According to Fig. 1c, a highly crystalline structure of monolithic HA was formed in the absence of nickel after the sintering process. With the addition of $6 \% \mathrm{Ni}$, the decomposition of $\mathrm{HA}$ to $\beta$-TCP and $\mathrm{CaO}$ was identified according to the following reaction:

$\mathrm{Ca}_{10-\mathrm{x}} \mathrm{Ni}_{\mathrm{x}}\left(\mathrm{PO}_{4}\right)_{6}(\mathrm{OH})_{2} \rightarrow 3 \mathrm{Ca}_{3-\mathrm{x} / 3} \mathrm{Ni}_{\mathrm{x} / 3}\left(\mathrm{PO}_{4}\right)_{2}+\mathrm{CaO}+\mathrm{H}_{2} \mathrm{O}$.

In the presence of $1.5 \% \mathrm{GNPs}$ (1.5Ni6), HA significantly decomposed to $\beta$-TCP due to the high thermal conductivity of the GNPs. In general, $\mathrm{HA}$ is a non-conducting ceramic that exhibits poor thermal $\left(1.25 \mathrm{~W} \mathrm{~m}^{-1} \mathrm{~K}^{-1}\right)$ and electrical $\left(7 \times 10^{-7} \mathrm{~S} \mathrm{~cm}^{-1}\right)$ conductivity [33]. However, due to the presence of GNPs in the composite, a thermal gradient was created between the GNPs and HA, which results in a severe decomposition. Therefore, the phase percentage of HA decreased to $14 \%$, while the percentage of $\beta$-TCP increased to $86 \%$. The measurement of structural features such as crystallite size, volume fraction of grain boundary and crystallinity degree of the modified HA is essential because the phase composition and transformation are dependent on these parameters. The average crystalline size of the nanopowders was determined using the Debye-Scherrer equation. In accordance with Fig. 2a, with an increase of the Ni content from 0 to $6 \%$, the crystallite size of the Ni-doped HA decreased drastically from $24 \pm 1$ to $11 \pm$ $1 \mathrm{~nm}$. After the calcination process at $900{ }^{\circ} \mathrm{C}$ for $1 \mathrm{~h}$, the crystallite size of pure $\mathrm{HA}$ increased notably to $56 \pm 3 \mathrm{~nm}$. A similar trend was observed in the presence of $\mathrm{Ni}$, where the crystallite size of $\mathrm{HA}$ increased to $45 \pm 2$ and $39 \pm 2 \mathrm{~nm}$ when the Ni content increased from 3 to $6 \%$, respectively.

If a crystallite is a sphere of diameter $D$ surrounded by a shell of grain boundary with thickness $t$, the volume fraction of the grain boundary $(f)$ may be estimated using the following formula [43]:

$$
f=1-\left[\frac{D}{(D+t)}\right]^{3}
$$

The $f$ values were determined by substituting the experimental crystallite size obtained by XRD into $D$ with the assumption that $t=1 \mathrm{~nm}$

From the obtained data, the $f$ values ranged from $5 \pm 1$ to $23 \pm 1 \%$. However, the volume fraction of grain boundary in the presence of 3 and $6 \% \mathrm{Ni}$ was higher than the pure HA (Fig. 2b). After the calcination process, the value of $f$ decreased dramatically for all the samples due to the HA crystal growth during the thermal treatment. This finding suggests that the substitution of an appropriate amount of $\mathrm{Ni}$ in the HA lattice can lead to the formation of modified HA with a finegrained structure. 

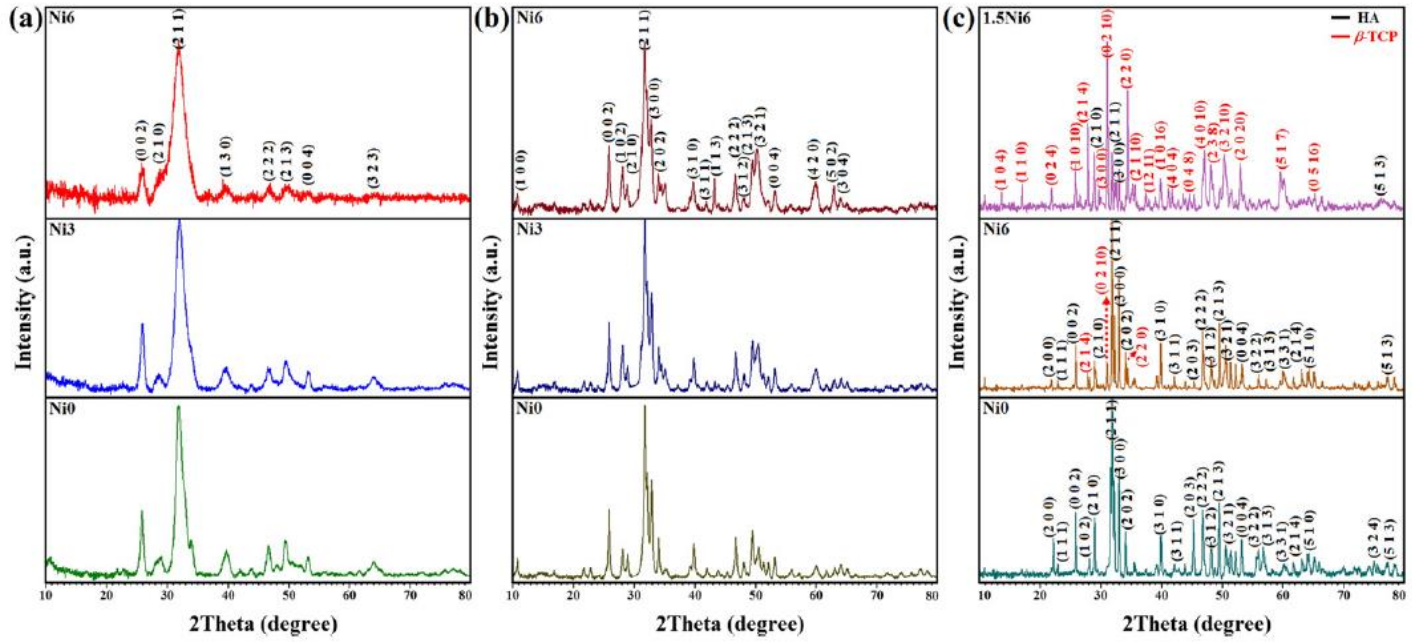

Fig. 1. XRD profiles of $\mathrm{NiO}, \mathrm{Ni3}$ and $\mathrm{Ni} 6$ (a) before and (b) after calcination and of (c) NiO, $\mathrm{Ni} 6$ and $1.5 \mathrm{Ni} 6$ after sintering.

The crystallinity degree of the specimens was determined from the XRD profiles using the following equation [44]:

$X c=1-\left(\frac{V_{112 / 300}}{I_{300}}\right)$,

where $X c$ is the crystallinity degree, $I_{300}$ is the intensity of the (300) peak, and $V_{112 / 300}$ is the intensity of the shoulder between the (112) and (300) diffraction peaks.

In the absence of $\mathrm{Ni}$ (pure $\mathrm{HA}$ ), the crystallinity degree of $\mathrm{HA}$ was approximately $30 \pm 2 \%$ (Fig. 2c). This value decreased to $14 \pm 1$ and $4 \pm$ $1 \%$ when the Ni content increased to 3 and $6 \%$, respectively. This finding indicates that the addition of $\mathrm{Ni}$ can affect the fraction of crystalline phase in the HA-based ceramics. During the calcination process, the crystallization of HA was dominant; therefore, the crystallinity degree increased sharply to $94 \pm 5 \%$ for pure $\mathrm{HA}$ and to $88 \pm 4$ and $64 \pm 3 \%$ for the modified-HA with 3 and $6 \% \mathrm{Ni}$, respectively. Indeed, apatites with higher crystallinity degree exhibit little or no activity toward bioresorption and are insoluble in physiological environment [45]. Therefore, all the calcined samples, especially pure $\mathrm{HA}$ and $3 \% \mathrm{Ni}$ substituted-HA, can be expected to exhibit greater chemical stability, which could be applicable in bone-tissue engineering. For $1.5 \mathrm{Ni} 6$, severe HA decomposition was observed, which caused a drastic reduction in the crystallinity degree up to $6 \pm 1 \%$.

The lattice constants ( $a, b$, and $c)$ and unit cell volume of HA as a function of Ni content are summarized in Table 1. For the standard HA
(JCPDS\#24-0033), the $a$-axis and c-axis values are 9.4320 and $6.8810 \AA$, respectively. In addition, the unit cell volume of HA is $530.14 \AA^{3}$. The calculated data indicates that these values fluctuated during the ion-exchange and calcination treatments. In the absence of $\mathrm{Ni}$, the $a$-axis and $c$-axis values were approximately 9.43264 and $6.89774 \AA$, respectively. In this case, HA exhibited a unit cell volume of approximately $531.501 \AA^{3}$. With the addition of $3 \% \mathrm{Ni}$, a reduction in the lattice constants occurred, and consequently, the unit cell volume reached $529.583 \AA^{3}$. A further increase in the Ni content to $6 \%$ led to a significant diminution in the unit cell volume of $\mathrm{HA}\left(V=528.303 \AA^{3}\right)$. These differences in the unit cell dimensions can most likely be attributed to the lattice distortion of HA during the ion-substitution process. It is apparent from Table 1 that the lattice parameters in the Ni-doped HA decreased significantly compared with undoped HA. This result is attributed to the replacement of the smaller $\mathrm{Ni}^{2+}$ (ionic radius $0.069 \mathrm{~nm}$ ) with the relatively larger $\mathrm{Ca}^{2+}$ (ionic radius $0.099 \mathrm{~nm}$ ) during the substitution process [46]. This phenomenon in turn is responsible for the changes in the crystallite size, which is in good agreement with the presented data in Fig. 1a, which indicates that the crystallite size of the product decreased with increasing Ni content from 0 to $6 \%$. During the calcination process at $900{ }^{\circ} \mathrm{C}$ for $1 \mathrm{~h}$, the recovery of the HA lattice occurred, and therefore, the unit cell volume values increased slightly and were close to the standard HA. Overall, these results confirmed the substitution of $\mathrm{Ni}$ in the HA lattice.

The EDS analysis was performed for several specimens, and typical results have been selected and presented in Fig. 3. For more accurate
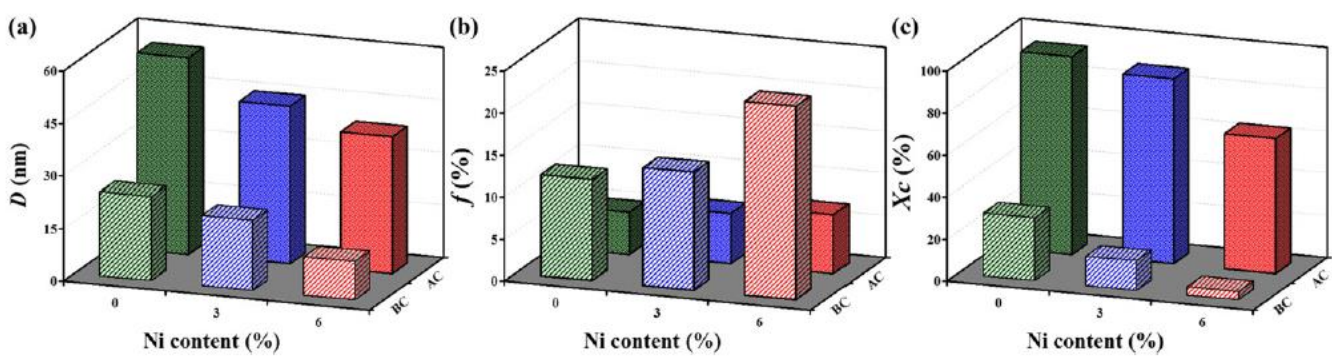

Fig. 2. (a) Crystallite size, (b) volume fraction of grain boundaries and (c) crystallinity degree of the modified HA. 
Table 1

Lattice constants ( $a, b$, and $c)$ and unit cell volume of $\mathrm{HA}$ as a function of Ni content.

\begin{tabular}{lllll}
\hline Composition & Calcination & $a=\mathrm{b}(\AA)$ & $c(\AA)$ & $V\left(\AA^{3}\right)$ \\
\hline HA & - & 9.43264 & 6.89774 & 531.501 \\
HA & $900^{\circ} \mathrm{C}, 1 \mathrm{~h}$ & 9.42975 & 6.88974 & 530.559 \\
$\mathrm{HA}-3 \% \mathrm{Ni}(\mathrm{Ni} 3)$ & - & 9.42893 & 6.87826 & 529.583 \\
$\mathrm{HA}-3 \% \mathrm{Ni}(\mathrm{Ni} 3)$ & $900{ }^{\circ} \mathrm{C}, 1 \mathrm{~h}$ & 9.42202 & 6.89076 & 529.768 \\
$\mathrm{HA}-6 \% \mathrm{Ni}(\mathrm{Ni} 6)$ & - & 9.41932 & 6.87564 & 528.303 \\
$\mathrm{HA-6 \%} \mathrm{Ni} \mathrm{(Ni6)}$ & $900^{\circ} \mathrm{C}, 1 \mathrm{~h}$ & 9.42029 & 6.89120 & 529.607 \\
\hline
\end{tabular}

results, EDS spectra were recorded over three different points on the specimens. The evaluation of the elemental constituents of pure HA revealed peaks belonging to calcium, phosphorus and oxygen. The EDS spectra were mainly used to determine the percentage of $\mathrm{Ni}$ in the HA lattice for Ni-doped HA. The average value of the tested areas indicated that the weight percentage of Ni was approximately $2.46 \mathrm{wt} . \%$ which was slightly lower than the ideal value (3\%) but within a reasonable range. This result confirms the presence of $\mathrm{Ni}$ in the HA lattice, which was not apparent in XRD profiles. From the EDS spectra, pure $\mathrm{HA}$ had a $\mathrm{Ca} / \mathrm{P}$ ratio of approximately 1.77 . In the presence of various percentages of Ni substitution, this ratio changed and reached approximately 1.62 in $3 \% \mathrm{Ni}$-doped HA. In addition, the $(\mathrm{Ca}+\mathrm{Ni}) / \mathrm{P}$ ratio was approximately 1.73 when the Ni content reached $3 \%$. These finding suggest that the values for $\mathrm{HA}$ and $\mathrm{Ni}$-doped HA crystals are closer to the expected value for the molar ratio of calcium to phosphorus in the stoichiometric $\mathrm{HA}(\mathrm{Ca} / \mathrm{P}=1.67)$. It is noteworthy that no chemically stable impurity was detected as a product of the subsequent milling

\subsubsection{FT-IR analysis}

Fig. 4 presents the FT-IR spectra of pure HA, Ni6 and $1.5 \mathrm{Ni} 6$. The functional groups of $\mathrm{HA}$, such as $\mathrm{PO}_{4}^{3-}, \mathrm{OH}^{-}$and $\mathrm{CO}_{3}^{2-}$, were detected in the $4000-400 \mathrm{~cm}^{-1}$ region in the FT-IR spectra [47-50]. The characteristic bands are assigned here:

(a) Two bands belonging to the vibration of the adsorbed water in $\mathrm{HA}$ appear at $3600-2600$ and $1800-1666 \mathrm{~cm}^{-1}$ [49].

(b) For the pure $\mathrm{HA}$, the bands at 1089 and $1018 \mathrm{~cm}^{-1}$ are attributed to $\nu_{3} \mathrm{PO}_{4}$; the band at $960 \mathrm{~cm}^{-1}$ is attributed to $\nu_{1} \mathrm{PO}_{4}$, and the peaks at 599 and $558 \mathrm{~cm}^{-1}$ are attributed to $\nu_{4} \mathrm{PO} 4[47,48]$. These bands were slightly shifted due to the substitution of $\mathrm{Ni}$ in the HA lattice as well as the addition of $1.5 \%$ GNP.

(c) Two regions of the FT-IR spectra are ascribed to the carbonate vibrations in HA: (i) $850-890 \mathrm{~cm}^{-1}$ corresponding to $\nu_{2}\left(\mathrm{CO}_{3}^{2-}\right)$ and (ii) $1420-1650 \mathrm{~cm}^{-1}$ belonging to $\nu_{3}$ vibrations of the carbonate groups [51]. The presence of the carbonated groups suggests that the as-prepared powders contained some $\mathrm{CO}_{3}^{2-}$ groups in the $\mathrm{PO}_{4}^{3-}$ sites of the apatite lattice (B-type substitution). It has

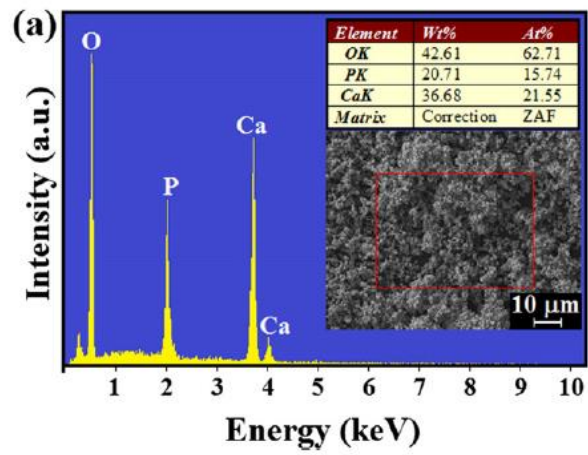

been reported that this type of HA is more similar to biological apatite and can be very useful as a bone replacement material $[52,53]$. However, the usefulness of CHA depends on the powder features such as the average particle size, surface area, and morphology [54].

(d) For 1.5Ni6, the characteristic bands of the methylene groups $\left(\mathrm{CH}_{2}\right)$, which are inherent in GNP, were detected at $2969 \mathrm{~cm}^{-1}$ and $2906 \mathrm{~cm}^{-1}$ [6]

(e) The FT-IR results indicated that in the presence of $\mathrm{Ni}$, the severity of the band overlap increased slightly compared with that of pure HA, which implies a minor decrease in the fraction of the crystalline phase (crystallinity degree). This result is in good agreement with the XRD results. In accordance with the FT-IR spectra, the synthesized powders exhibited high chemical purity, which is crucial in biomedical applications.

\subsubsection{Raman analysis}

Raman spectroscopy was performed to characterize the defect density, number of layers and crystallinity of the GNP structure in the composites. Typical Raman spectra of the samples are presented in Fig. 5. The $\mathrm{G}$ and $2 \mathrm{D}\left(\mathrm{G}^{\prime}\right)$ peaks appear due to the $\mathrm{C}-\mathrm{C}$ bond plane stretching in GNP, where the 2D peak is related to the number of graphene layers, and the D peak corresponds to the defect density introduced in the structure. The presence of a small intensity D peak relative to the $G$ peak in the pristine GNP indicates a very small defect density. Moreover, a 2D peak at $\sim 2690 \mathrm{~cm}^{-1}$ is observed, which is typical of a multilayer sheet or platelet configuration of the GNP [55].

The Raman spectrum of the composite powder exhibits significant changes compared with that of GNP. Both the G and D bands are shifted toward higher wave numbers of 1349 and $1584 \mathrm{~cm}^{-1}$, respectively. A shift in the $\mathrm{G}$ band toward higher wave numbers indicates an increase in the defect density in the graphene structure [56]. The intensity ratio of the $\mathrm{D}$ to $\mathrm{G}$ bands $\left(\mathrm{I}_{\mathrm{D}} / \mathrm{I}_{\mathrm{C}}\right)$ is a measure of the disorder degree and the average size of the $\mathrm{sp}^{2}$ domains. The $\mathrm{I}_{\mathrm{D}} / \mathrm{I}_{\mathrm{G}}$ ratios for the GNP and $1.5 \mathrm{Ni} 6$ composite powder were 0.26 and 0.71 , respectively (Table 2 ). This result indicates an increase in the defect density in the GNP, which is most likely due to the ball-milling process. The ball milling of $1.5 \mathrm{Ni} 6$ powders produced strong interactions between the GNP and Ni6 particles. These interactions on the GNP resulted in a lower $I_{2 D} / I_{C}$ ratio, which indicates partial loss of the graphene-like structure [57]. For the sintered samples, the $\mathrm{I}_{\mathrm{D}} / \mathrm{I}_{\mathrm{G}}$ ratio increased from 0.71 to $0.93 \mathrm{com}$ pared with the composite powder, which might indicate some defect density introduced during the sintering process. The sintered samples tend to have higher $\mathrm{I}_{\mathrm{D}} / \mathrm{I}_{\mathrm{G}}$ and lower $\mathrm{I}_{2 \mathrm{D}} / \mathrm{I}_{\mathrm{G}}$ ratios compared with the GNP powder. Moreover, previous studies have reported that a decrease

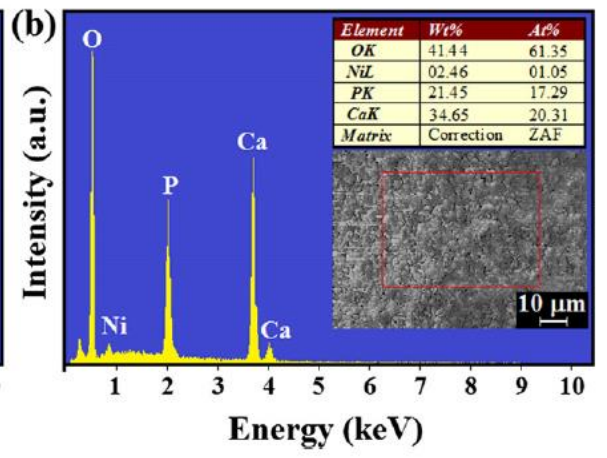

Fig. 3. EDS analysis of the as-prepared powders: (a) pure HA and (b) 3\% Ni-doped HA 

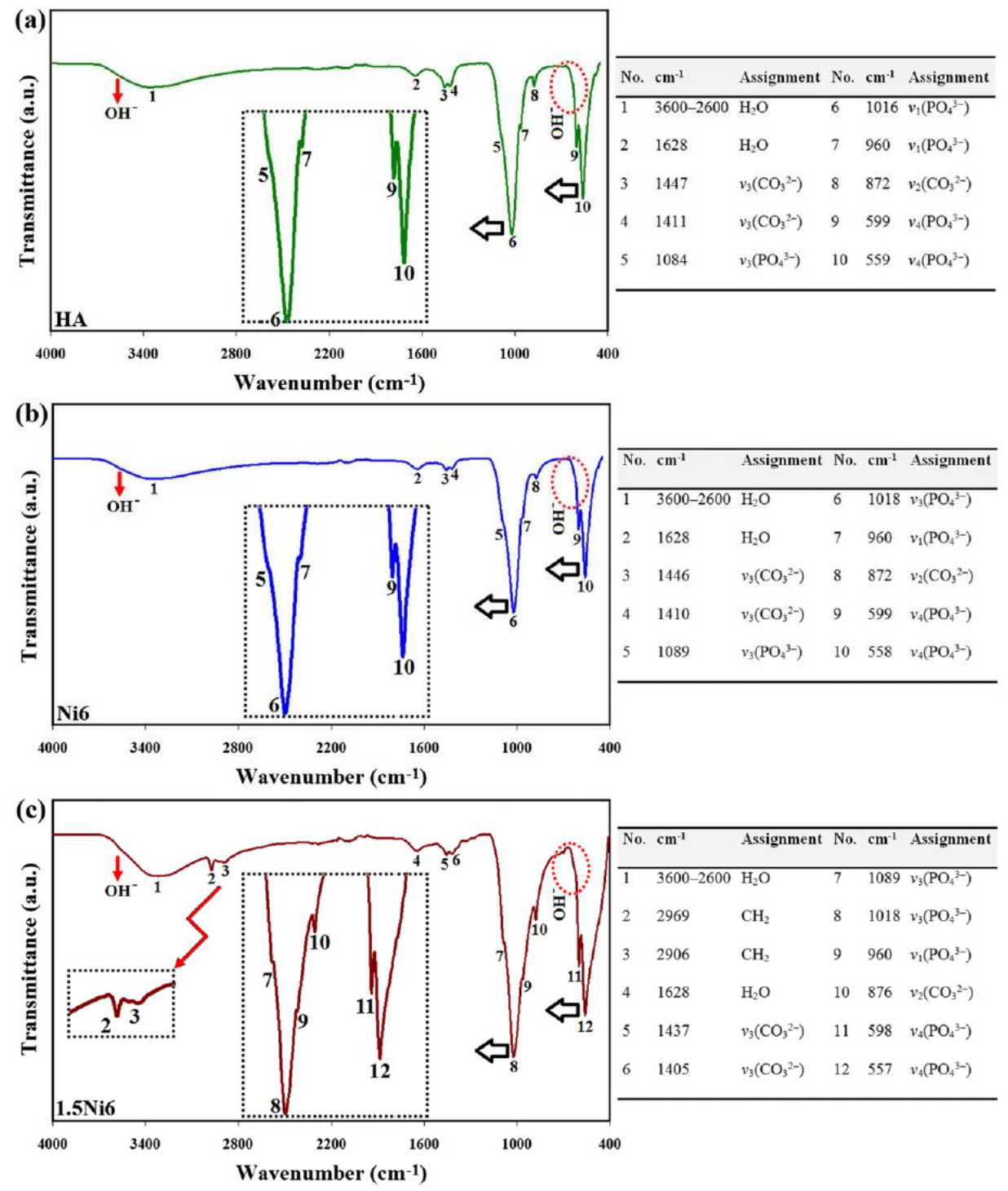

Fig. 4. FT-IR spectra of the as-prepared powders: (a) pure HA, (b) Ni6 and (c) $1.5 \mathrm{Ni} 6$

in the intensity ratio of $\mathrm{I}_{2 \mathrm{D}} / \mathrm{I}_{\mathrm{G}}$ and the appearance of a narrow and sharp 2D peak compared with the pristine GNP are due to the increase of graphene layers. Moreover, the peak at $\sim 2940 \mathrm{~cm}^{-1}$ is attributed to the $\mathrm{D}+\mathrm{D}^{\prime}$ band, which is generally related to point defects in the basal plane or edges of single-crystalline graphene domains. The increase in the intensity of the $D+D^{\prime}$ peak at $\sim 2940 \mathrm{~cm}^{-1}$ indicates better graphitization $[58,59]$.

The Raman spectrum of $1.5 \mathrm{Ni} 6$ contains an intense peak at $961 \mathrm{~cm}^{-1}$, which is associated with the symmetric $\left(\vartheta_{1}\right)$ P-O-P stretching mode of the free tetrahedral phosphate ion. After the sintering process, the peak at $961 \mathrm{~cm}^{-1}$ was observed to have higher intensity than the composite powder. The other peaks that are relevant to the phosphate modes appeared at different wave numbers, such as $1049 \mathrm{~cm}^{-1}\left(\vartheta_{3} \mathrm{PO}_{4}\right)$,
$591 \mathrm{~cm}^{-1}\left(\vartheta_{4} \mathrm{PO}_{4}\right), 433 \mathrm{~cm}^{-1}\left(\vartheta_{2} \mathrm{PO}_{4}\right)$, and a weak band appeared at $273 \mathrm{~cm}^{-1}$, which is assigned to $\mathrm{Ca}-\mathrm{PO}_{4}[14]$. The above results confirmed that the composite was composed of GNP and HA.

\subsection{Microstructural and mechanical properties}

The as-received graphene sheets used in this study were $1-20 \mathrm{~nm}$ in thickness and 1-50 $\mu \mathrm{m}$ in width. FESEM images of the raw graphene at both low and high magnifications are presented in Fig. 6 ( $\mathrm{a}$ and b). It can be observed that the majority of the graphene sheets tend to agglomerate and were bundled together. In fact, several smaller graphene flakes are assembled into larger graphene blocks. In addition, the graphene sheets possess a large aspect ratio, which is the main factor for the 


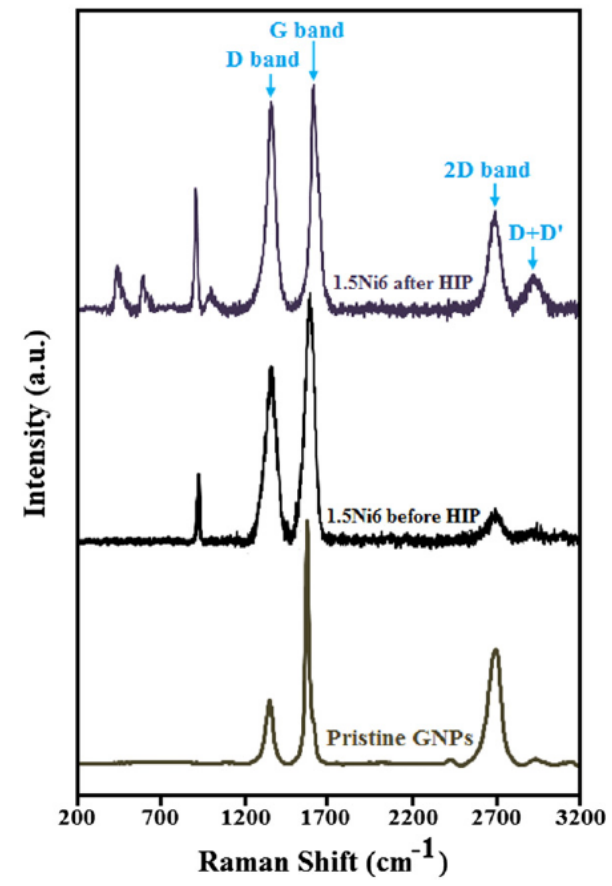

Fig. 5. Raman spectra of pristine GNP and $1.5 \mathrm{Ni} 6$ before HIP and $1.5 \mathrm{Ni} 6$ after HIP.

intensification of the contact area with the other phases. The FESEM images indicate that the GNPs are very thin with some wrinkles and folding [32,60]. Fig. 6 (c and d) shows the typical microstructure of the $1.5 \mathrm{Ni} 6$ composite powder at both low and high magnifications. As mentioned above, the calcined Ni6 powder as a matrix exhibited intrinsic expansion during the initial stage of thermal treatment. Finally, the grain coalescence and decrease in the number of grains occurred due to superficial diffusion and grain boundary sliding, respectively [61]. The FESEM images reveal the nanocrystalline nature of the composite powder and demonstrate that the specimens are composed of spheroidal particles with an average particle size of approximately $100 \mathrm{~nm}$. Because HA granules with a smooth spherical geometry are helpful in osseointegration, the synthesized powder can be considered in bone tissue-engineering applications [62]. In addition, it is apparent that the graphene nanoplatelets are well distributed in the composite powder with improved mechanical behavior and biological responses [63]. However, the particles exhibited a relatively high tendency to agglomerate. When two adjacent primary particles collide, coalescence may occur on the premise that these two particles share a common crystallographic orientation. As a result, the two primary particles attach to each other and combine to form a secondary particle. Because the sizes of the secondary particles are still very small, it is reasonable that the particles will continue to collide and coalesce. This behavior will ultimately lead to the agglomeration $[53,64]$.

Table 2

Peak position of the $D$ and $G$ bands and intensity ratios of $\mathrm{I}_{\mathrm{D}} / \mathrm{I}_{\mathrm{G}}$ and $\mathrm{L}_{\mathrm{D}} / \mathrm{I}_{\mathrm{G}}$.

\begin{tabular}{lllllll}
\hline $\begin{array}{l}\text { Sample's } \\
\text { name }\end{array}$ & $\begin{array}{l}\mathrm{D} \text { band } \\
\text { Raman shift }\end{array}$ & $\begin{array}{l}\mathrm{G} \text { band } \\
\text { Raman shift }\end{array}$ & $\begin{array}{l}\text { 2D band } \\
\text { Raman shift }\end{array}$ & $\begin{array}{l}\mathrm{D}+\mathrm{D}^{\prime} \\
\text { Raman shift }\end{array}$ & $\mathrm{I}_{\mathrm{D} / \mathrm{I}_{\mathrm{G}}}$ & $\mathrm{I}_{2 \mathrm{D}} / \mathrm{I}_{\mathrm{G}}$ \\
\hline GPL & 1347 & 1570 & 2690 & 2928 & 0.26 & 0.48 \\
1.5Ni6 BFS & 1349 & 1584 & 2707 & 2942 & 0.71 & 0.44 \\
1.5Ni6 AFS & 1349 & 1603 & 2708 & 2978 & 0.93 & 0.25 \\
\hline
\end{tabular}

To evaluate the distribution of GNPs in the composite structure, the cross-section of a typically sintered sample containing $1.5 \%$ GNPs (1.5Ni6) was examined (Fig. 7). The FESEM micrographs show that apart from the distribution, the local contacts between the modified HA and the fully exfoliated graphene are obvious (Fig. 7a). The position of the embedded GNPs is indicated by the red arrows. This figure verifies the good dispersion of graphene nanoplatelets in the composite structure. Moreover, the cross-sectional view of the graphene laminates reveals stacks of graphene platelets that might affect the degree of mechanical improvement. To overcome this problem, further separation of aggregates as well as the prevention of the GNP agglomeration would be useful [65]. As observed in Fig. 7b, nano-scaled pores are formed during the sintering of the composite. It has been observed that an increase in the porosity of the HA composite might more or less deteriorate its mechanical properties. However, from the biological viewpoint, these nano-sized pores contribute to osteoblast in-growth of the composite [32].

The relative density and mechanical properties of the samples (elastic modulus, hardness and fracture toughness) are summarized in Table 3. According to the presented data, the sintered monolithic HA, Ni6 and $1.5 \mathrm{Ni} 6$ composites exhibit high relative densities. All the samples are fully densified at $1150^{\circ} \mathrm{C}$ and $160 \mathrm{MPa}$ pressure during the HIP sintering. Previous reports demonstrated that the use of GNP as a reinforcement material has a significant effect on increasing or decreasing the relative density, which depends on the mixing process, sintering method and types of graphene. Zhao et al. [31] reported that the relative density of GNPs/BCP decreased with the addition of different ratios of GNPs compared with pure HA. Nieto et al. [57] observed that with the addition of GPL to TaC, the densification of the composites increased to $60 \%$ compared with that of monolithic TaC. Yadhukulakrishnan et al. [66] reported that the reinforcement of GNPs favors the high densification of composites through the interfacial reaction, which can be retained in the composites sintered at high temperature. However, there are no reports that discuss the effect of metal ions on the density of the dopant composites. Herein, the substitution of $\mathrm{Ni}$ in the HA lattice has little effect on the increase of the dopant composite density. However, the relative density of apatites may enhance the presence of GNPs such that the relative density of the $1.5 \mathrm{Ni} 6$ (1.5\% GNPs) increased compared with the monolithic HA and Ni6. This behavior was due to the large surface area of the GNPs, which increases the surface diffusion during sintering. The measurement of the elastic modulus in bioceramic applications was performed using the nanoindentation technique in this experiment. The results revealed a significant increase in the $\mathrm{E}$ value for the Ni dopant by $120 \%$ over the monolithic HA. Based on our previous studies, at a very low concentration of graphene, the elastic modulus of composites improved compared with that of monolithic HA due to the intrinsic properties of the graphene nanosheets, the homogenous distribution of GNPs in the matrix and strong Ni6/GNPs interfaces. All the samples exhibited high moduli of elasticity between graphene concentrations of $1-1.5 \%$ in the composites. In a similar trend in Table 3, it is clearly observed that the elastic modulus of $1.5 \mathrm{Ni} 6$ ( $1.5 \% \mathrm{GNPs}$ ) increases to $85 \%$ compared with that of monolithic HA. As mentioned previously (XRD data), severe HA decomposition occurred during the sintering of the composite $(1.5 \mathrm{Ni6})$ at $1150{ }^{\circ} \mathrm{C}$ due to the high thermal conductivity of the GNPs. Therefore, the coexistence of HA and $\beta-T C P$ in the composite could explain the decrease of the elastic modulus in the composite sintered at $1150{ }^{\circ} \mathrm{C}$. To calculate the hardness and fracture toughness values, microindentation ( $\geq 5 \mathrm{~kg}$ ) was conducted because indentation of presented composite did not generate a welldefined radial crack system. From Table 3 , it is apparent that the $\mathrm{Ni}$ dopant increased the hardness as much as $55 \%$ due to its hard intrinsic properties compared with the monolithic HA. The microhardness improvement in $1.5 \mathrm{Ni6}$ can be attributed to (i) the uniform dispersion of GNPs in the HA matrix, (ii) the prevention of localized plastic deformation due to the presence of GPL and (iii) the small amount of porosity due to an appropriate sintering process. According to the results in Table 3, the Ni dopant plays a significant role in increasing the fracture toughness of the bulk samples. The Ni6 composite exhibits improved fracture

Link to Full-Text Articles :

http://www.sciencedirect.com/science/article/pii/s0928493115000600 